\title{
ВЛИЯНИЕ РОБОТОТЕХНИКИ И ТРУДОСБЕРЕГАЮЩИХ ТЕХНОЛОГИЙ НА ДЕМОГРАФИЧЕСКИЕ ПРОЦЕССЫ: ТРЕНДЫ И СЦЕНАРИИ
}

\author{
АЛЕКСАНДР АКИМОВ
}

\begin{abstract}
Развитие робототехники и других трудосберегающих технологий (станки с числовым программным управлением, аддитивные технологии, искусственный интеллект, крупные производительные комплексы в горнодобывающей промышленности) вытесняет человека из сферы производства. Суженный рынок труда будет воздействовать на рождаемость, финансирование здравоохранения (а через него на смертность) и миграции как международные, так и внутренние, особенно в развивающихся странах. Вытеснение женщин с рынка труда может повысить рождаемость, особенно если будет распространен базовый фиксированный доход на каждого жителя страны. $B$ то же время безработица может существенно понизить желание иметь детей и рождаемость. Искусственный интеллект в медицине может повысить качество и понизить стоимость медицинских услуг, положительно влияя на здравоохранение и понижая смертность, но сокращение подоходных налогов и снижение личных доходов будет ограничивать финансирование здравоохранения, что может замедлить или даже прекратить рост продолжительности жизни. В то же время развитие трудосберегающих технологий решит проблему нехватки рабочей силь изза старения населения. Современная география международных миграций может претерпеть резкие изменения, поскольку трудовые иммигранты в развитых странах будут не нужны. Для развивающихся стран сложившаяся в ХХ веке модель модернизации, включающая индустриализацию и урбанизачию, может разрушиться из-за сокращения рынка труда в современных отраслях промышленности и сферы услуг, а урбанизация без индустриализации, как показывает опыт 1960 2005 г2., чревата кровопролитными политическими волнениями.

В результате широкого использования трудосберегающих технологий могут сформироваться как благоприятнье сценарии демографического развития, так и негативные. Вариантьл в значительной степени будут зависеть от управления социальными и демографическими процессами.
\end{abstract}

Ключевые слова: робототехника, трудосберегающие технологии, рождаемость, здравоохранение, смертность, миграции, урбанизация, тренды, сиенарии.

\section{ТРУДОСБЕРЕГАЮЩИЕ ТЕХНОЛОГИИ}

В последние годы накапливавшиеся в течение десятилетий успехи в развитии разных технологий привели к созданию широчайшего спектра производств, в которых человек практически не нужен. Такая ситуация кардинально меняет сложившуюся систему социальных и экономических отношений.

Робототехника - наиболее заметная часть новых технологий в области трудосбережения, но помимо нее успешно развивается целый ряд других технологий, приводящих к тем же последствиям для рынка труда, что и робототехника.

АЛЕКСАНДР ВЛАДИМИРОВИч АКИМов (akimovivran@mail.ru), ИНСТИТУТ вОСТОКОВЕДЕНИЯ РАН, РосСИЯ.

СТАТЬЯ ПОСТУПИЛА В РЕДАКЦИЮ в ФЕВРАЛЕ 2017 Г. 
К таким технологиям относятся станки с числовым программным управлением (ЧПУ), искусственный интеллект, аддитивные технологии, а также создание крупных машин и их комплексов для горных работ и перевалки насыпных грузов. Кроме того, существуют уже привычные технологии, которые в свое время (несколько десятилетий назад) произвели революционные изменения в ряде отраслей.

Роботы отличаются от станков с ЧПУ большим количеством степеней свободы при выполнении работ, но станки с ЧПУ выполняют работу по программе, так же как и роботы, вытесняя квалифицированный персонал (станочников). Искусственный интеллект в основном заменяет лиц умственного труда, включая низкоквалифицированных инженеров, офисных работников, а также врачей при диагностике и даже преподавателей при проверке эссе студентов, так как эти системы способны обучаться, если в них введены работы, ранее оцененные преподавателями [Форд 2016: 177-180].

Из аддитивных технологий наиболее известны трехмерные лазерные принтеры, способные распечатать трехмерное изделие по программе путем послойного нанесения пластических масс с различными добавками. Цельный предмет получается путем склеивания или спекания.

Крупные машины в горном деле отличаются большой производительностью, способны переваливать огромное количество породы, что вытесняет подземный способ добычи, где нужны шахтеры, заменяя его карьерным способом разработки месторождений.

Примерами старых технологий в области трудосбережения являются механизация сельского хозяйства, контейнерные перевозки, вытеснившие докеров в портах, магазины самообслуживания и торговые автоматы, заменяющие продавцов, дистанционное банковское обслуживание и банкоматы.

Таким образом, в современной экономике накоплены многочисленные технологии, заменяющие человека и при этом не только не ухудшающие результат, а в большинстве случаев повышающие производительность и качество, снимая человеческий фактор в производстве.

Перечисленные технологии развиваются, их внедрение расширяется. Уже можно определить тренды и их влияние на социально-экономические процессы в различных частях мировой экономики.

Можно отметить, что проблема автоматизации производства как важнейшая для социально-экономического развития была отмечена экономистами еще в середине XX века. Например, В. Леонтьев в своей статье 1952 г. «Машины и человек» писал: «С технической точки зрения началась эра автоматического управления» [Леонтьев 1990: 185]. Далее В. Леонтьев описывает тенденции в производстве, связанные с автоматизацией: «Человек почти перестал выполнять работу по подъему и перемещению грузов; его функции прежде всего состоят в том, чтобы запускать и останавливать оборудование, выполнять операции по его наладке, сборке и ремонту. С внедрением самоуправляющихся машин рамки его прямого участия в процессе производства сузятся еще больше. Прежде всего, не будет операций по пуску и остановке, следом исчезнут операции по наладке и сборке. Конечно, аварийные и ремонтные службы еще долгое время не останутся без работы. Необходимость 
в них даже возрастет, так как высокочувствительное и сложное оборудование для автоматического управления будет требовать квалифицированного ухода. Нам попрежнему будут требоваться изобретатели и проектировщики, однако, может быть, даже их не понадобится слишком много: главный инженер одной крупной фирмы, выпускающей электронное оборудование, недавно в беседе со мной выразил вполне обоснованную надежду, что в недалеком будущем разработка схем будет осуществляться электронными машинами, что исключит «человеческие» ошибки» [Леонтьев 1990: 193].

Таким образом, еще 70 лет назад все основные тенденции в развитии технологий, влияющие на рынок труда, были предсказаны.

Формирование крупных транснациональных компаний, перенос ими производства в развивающиеся страны и формирование модели догоняющего развития на основе экспорта из менее развитых стран с более дешевой рабочей силой в более развитые и богатые привели к тому, что трудосберегающие технологии вынуждены были конкурировать с дешевой рабочей силой в развивающихся странах, и в течение ряда десятилетий они эту конкуренцию проигрывали.

Последствия развития автоматизации производства анализировал и отечественный исследователь Э.А. Араб-Оглы [1986]. В частности, он рассмотрел доклад Римскому клубу «Микроэлектроника и общество: на радость и на горе» [Friedrichs, Schaff 1982], в котором, в частности, говорилось следующее: «Микроэлектронная революция несомненно изменит роль труда в человеческой жизни, уменьшив потребность в нем, а в некоторых случаях и полностью его исключив» [Араб-Оглы 1986: 141].

С конца 1980-х годов всеобщее внимание привлекло развитие информационных технологий, которые стали влиять на жизнь широких слоев граждан сначала развитых, а потом и развивающихся стран. Новые технологии развивались в значительной степени как услуги для потребителей, а не как средства производства, что и привело к тому, что роботизация долгое время не была предметом внимания. Например, в книге нобелевского лауреата по экономике М. Спенса «Следующая конвергенция: будущее экономического роста в мире, живущем на разных скоростях» в качестве значимых для будущего технологий рассмотрены только новая энергетика и информационные технологии [Спенс 2013].

Мобильная связь и Интернет отодвинули в информационном поле робототехнику на второй план, но она развивалась достаточно успешно. Сейчас же итоги этого развития представляются несколько неожиданными, но на самом деле они появились в результате долговременного процесса, который был предсказан рядом экспертов за несколько десятилетий до того, как этот процесс привлек внимание широкой общественности.

\section{ПРИМЕРЫ ИСПОЛЬЗОВАНИЯ ТРУДОСБЕРЕГАЮЩИХ ТЕХНОЛОГИЙ}

В последние годы накапливавшиеся в течение десятилетий успехи в развитии разных технологий привели к созданию широчайшего спектра производств, в которых роль человека минимальна [Акимов 2016b]. Вот несколько примеров использования 
трудосберегающих технологий в разных сферах хозяйства.

Примером минимизации участия человека в добывающей промышленности может служить Австралия. Отмечаются две тенденции в развитии основного экспортного минерального продукта Австралии - железной руды. Первая, продолжающаяся уже довольно продолжительное время, - это создание крупных производительных комплексов. Вторая, наметившаяся недавно, - роботизация горных работ.

Составляющие первой тенденции: концентрация производства в небольшом числе крупных комплексов с очень производительным оборудованием, создание надежной транспортной инфраструктуры, способной обеспечить перевозку больших объемов насыпных грузов, создание морских портов для экспорта руды.

Основная часть запасов железной руды в Австралии размещается в месторождениях штата Западная Австралия, площадь которого составляет чуть более 2,5 млн квадратных километров, что сопоставимо по площади с территорией Западной Сибири. В пустынной части, которая обеспечивает производство железной руды на экспорт, живет примерно 200 тыс. человек, что примерно соответствует населению Норильска в России. Проблема рабочей силы решается использованием очень производительного оборудования. Это специализированные погрузчики для руды, гидравлическая разгрузка приезжающих составов с рудой и автомобилей. Для транспортировки применяются большегрузные поезда, растягивающиеся на 2 км, способные перевозить до 25 тыс. тонн руды каждый. Автопоезда перевозят до 300 тонн руды за рейс ${ }^{1}$.

Второе направление реализуется недавно, но набирает силу. Пока это использование driverless trucks, т.е. грузовиков без водителей. Несколько десятков таких грузовиков работают на карьере, а управляются из города Перта за 1200 км от рудника²

Таким образом, добывающая промышленность, ранее дававшая заработок малоквалифицированным горнякам, часто выходцам из сельской местности, перестала быть ступенькой в индустриальный мир для многочисленных выходцев из сельской местности.

Второй пример касается обрабатывающей промышленности. Автомобильная промышленность остается важной отраслью с большими объемами выпуска и высокой занятостью. Большинство промышленно развитых стран производят автомобили, и для развивающихся стран с догоняющей моделью развития создание на своей территории автомобильной промышленности было важным шагом на пути социально-экономической модернизации за счет создания большого количества рабочих мест, требующих квалификации работников и обеспечивающих высокие зарплаты.

Развитие робототехники и станков с числовым программным управлением существенно повышает производительность труда в автопроме и делает

\footnotetext{
${ }^{1}$ http://www.australianminesatlas.gov.au/education/fact_sheets/iron.html_(дата обращения: 20.10.2016).

${ }^{2}$ http://www.abc.net.au/news/2015-10-18/rio-tinto-opens-worlds-first-automated-mine/6863814 (дата обращения: 14.11.2016).
} 
безальтернативным применение роботов и станков с ЧПУ, поскольку они обеспечивают более высокое качество продукции, чем человек.

Если сопоставить занятость и выпуск в автомобильной промышленности США и КНР, то получается такая картина. В США в этой отрасли занято около 1 млн человек (914 тыс. по данным $\left.{ }^{3}\right)$, в КНР - 3,5 млн человек ${ }^{4}$. КНР производит в два раза больше автомобилей (24,5 млн автомобилей всех видов в КНР и 12,1 млн - в США в 2015 г.) [ОICА 2015].

Таким образом, в целом по отрасли производительность труда в КНР примерно в два раза ниже, чем в США, т.е. разрыв между страной, которая всегда была лидером по производительности труда, и страной с избыточной рабочей силой не особо велика. Такая же ситуация и в других отраслях, поскольку во всех странах устанавливается однотипное производительное оборудование и не остается рабочих мест, которые могли бы занять многочисленные малоквалифицированные безработные.

Еще одна ситуация касается сферы услуг. В США работа в ресторанах быстрого обслуживания является большой нишей для низкоквалифицированного дешевого труда. Когда в 2011 г. компания McDonald's объявила о приеме на работу 50 тыс. человек, она получила 1 млн заявлений от претендентов [Форд 2016: 35]. Уже разработаны и производятся роботы, которые готовят гамбургеры без участия человека. Поскольку средний ресторан в США тратит на зарплату сотрудникам, занятым приготовлением гамбургеров, примерно 130 тыс. долл. в год, приобретение робота будет окупаться менее, чем за год. По всему миру в ресторанах McDonald's занято около 1,8 млн человек, так что нововведение затронет большой рынок труда [Форд 2016: 31-32].

Примером конкуренции искусственного интеллекта и человека может служить вытеснение биржевых брокеров и ряда других сотрудников фирм, торгующих на бирже, автоматизированными системами анализа и торговли. За 2000-2013 гг. при весьма значительном росте объемов и интенсивности биржевой торговли на Уолл-стрит число работающих там финансистов сократилось со 150 тыс. человек до, примерно, 50 тыс. [Форд 2016: 158].

Современные трудосберегающие технологии приводят к тому, что новые производственные мощности, вводимые в самых разных сферах экономики, требуют гораздо меньшего числа рабочих мест. Относительно новым является то, что более производительными становятся рабочие места в сфере услуг также за счет применения новых технологий. Как отмечает президент Всемирного экономического форума в Давосе К. Шваб: «Многие категории профессий, в частности, те, что предусматривают механический монотонный и точный ручной труд, уже автоматизированы. За ними последуют другие категории, поскольку вычислительные мощности продолжают расти в геометрической прогрессии. Такие профессии, как юристы, финансовые аналитики, врачи, журналисты, бухгалтеры, страховые агенты или библиотекари, могут быть частично или полностью автоматизированы значительно раньше, чем можно предположить. На сегодняшний день складывается следующая ситуация: четвертая промышленная

\footnotetext{
${ }^{3}$ https://www.bls.gov/iag/tgs/iagauto.htm (дата обращения: 20.02.2017).

${ }^{4}$ http://www.ifr.org/news/ifr-press-release/world-robotics-report-2016-832/ (дата обращения: 20.01.2017).
} 
революция создает меньше рабочих мест в новых отраслях, чем предыдущие революции» [Шваб 2017: 51].

\section{ТРУДОСБЕРЕГАЮЩИЕ ТЕХНОЛОГИИ И ДЕМОГРАФИЧЕСКИЕ ПРОЦЕССЫ}

Демографическая система как подсистема общества не может остаться в стороне от этих изменений. А.Г. Вишневский и Р.В. Дмитриев выделяют следующие глобальные демографические процессы в XX - начале XXI века: переход к новой эпидемиологической модели и удлинение человеческой жизни, переход к новой репродуктивной стратегии и снижение рождаемости, мировой демографический взрыв, становление новой возрастной структуры населения, поворот международных миграций, урбанизация и внутренние миграции [Вишневский, Дмитриев 2016: 197-229].

Развитие трудосберегающих технологий прямо или косвенно окажет влияние на все эти процессы.

\section{Переход к новой эпидемиологической модели и удлинение}

\section{человеческой жсизни}

Здесь есть две тенденции, которые по-разному проявятся в развитых и развивающихся странах.

При современном далеко зашедшем в развитых странах старении населения разработки в биологии и медицине, а также фармакологии привели к появлению множества средств для сохранения здоровья в пожилом возрасте и активного долголетия. Большинство из этих разработок недешевы. Современное здравоохранение становится все более высокотехнологичным, что приводит к необходимости увеличивать расходы на диагностику и лечение.

Богатые страны тратят значительные средства на здравоохранение. По отношению к ВВП они наиболее высоки в США, но для стран с разным уровнем экономического развития и разными национальными системами здравоохранения этот показатель высок (таблица 1). При высоком уровне социально-экономического развития, но больших, чем в США, государственных расходах в Норвегии расходы на здравоохранение приближаются к 10\% ВВП. В гораздо более бедной Кубе, сделавшей ставку на развитие здравоохранения, при преобладании государственных расходов уровень затрат на здравоохранение выше $10 \%$ ВВП.

Таблица 1. Расходы на здравоохранение в 2014 г.

\begin{tabular}{|c|c|c|c|c|}
\hline & $\begin{array}{c}\text { Расходы на душу населения, } \\
\text { долл. США по паритету } \\
\text { покупательной способности }\end{array}$ & $\begin{array}{c}\text { Расходы на } \\
\text { здравоохранение к } \\
\text { ВВП, \% } \\
\end{array}$ & $\begin{array}{c}\text { Государственные } \\
\text { расходы, } \%\end{array}$ & $\begin{array}{c}\text { Частные } \\
\text { расходы, \% }\end{array}$ \\
\hline США & 9402,54 & 17,14 & 48,30 & 51,70 \\
\hline Норвегия & 6346,62 & 9,72 & 85,49 & 14,53 \\
\hline Куба & 2474,62 & 11,06 & 95,61 & 4,39 \\
\hline Китай & 730,52 & 5,55 & 55,79 & 44,21 \\
\hline Индия & 267,41 & 4,69 & 30,04 & 69,96 \\
\hline
\end{tabular}

Источник: [WHO 2017]. 
Крупнейшие по численности населения государства мира Китай и Индия имеют аналогичную США модель финансирования здравоохранения с упором на частные расходы, но там расходы ниже более чем в 10 раз. И для США, и для КНР, и для Индии, а также всех стран, имеющих аналогичную модель финансирования здравоохранения, сокращение частного финансирования на фоне старения населения чревато ухудшением здоровья населения и прекращением роста продолжительности жизни.

Сильно роботизированная экономика, в которой будет велика роль государства в перераспределении благ, будет нуждаться лишь в ограниченном количестве работников, связанных с производством и обслуживанием трудосберегающей техники. Судьбу остальных опять же будет решать государство, доминирующее в социальной сфере, поскольку большая часть населения не будет иметь источников заработка. Еще раз отметим, что рациональных экономических причин для поддержания долголетия в массовых масштабах не будет, что создает потенциальную опасность регресса в этой части воспроизводства населения, конкретно - прекращения роста продолжительности жизни по экономическим причинам. На примере США это может выглядеть так. Сложившаяся там мощная индустрия здравоохранения, которая обеспечивает развитие новейших технологий и практик в области здравоохранения, стала большим бизнесом. На эту сферу в США тратится 17\% ВВП, причем финансирование поделено практически пополам между государством и частными лицами. При сокращении доходов частных лиц при широком распространении роботов, станков с ЧПУ, аддитивных технологий и искусственного интеллекта разрушится модель коммерческого здравоохранения, которое в значительной степени поддерживает рост продолжительности жизни.

Есть и другая тенденция. Удешевление хотя бы части медицинских услуг может произойти за счет развития искусственного интеллекта и его применения в медицине. Централизованная система диагностики потенциально способна оперативно обрабатывать медицинскую информацию и ставить диагнозы в удаленном режиме для неограниченного числа пациентов. Может быть построена медицинская система централизованной диагностики на основе искусственного интеллекта типа уже существующей системы Watson $^{5}$, с которой соединены первичные пункты сбора медицинской информации, где средний медицинский персонал собирает анализы и вводит в компьютерную систему симптомы пациента. Данные пересылаются в централизованную систему диагностики и выдачи рекомендаций на основе симптомов и анализов. Естественно, такая система не включает медицинские манипуляции и операции, но терапия и ранняя диагностика ей под силу. Она обеспечит удешевление медицинских услуг при сокращении доходов среднего класса, что гарантирует достаточно высокий уровень медицинской помощи при сокращении расходов на медицину.

Для развивающихся стран, если рост частных доходов замедлится из-за высокой безработицы, остается кубинская модель развития здравоохранения, основанная на преобладающем финансировании государством этой области.

\footnotetext{
${ }^{5}$ http://www-03.ibm.com/press/us/en/presskit/27297.wss (дата обращения: 23.03.2017).
} 


\section{Переход к новой репродуктивной стратегии и снижсение рождаемости, мировой демографический взрыв}

Максимальное сокращение младенческой и детской смертности, обеспечивающее выживание практически всех рожденных детей и их дожитие до взрослого возраста, сделало процесс воспроизводства поколений очень экономным с биологической точки зрения, поскольку каждое рождение почти наверняка обеспечивает то, что ребенок будет жить долго. На этом фоне борьба за права женщин вовлекла их в работу за пределами домохозяйства. Вероятно, можно утверждать, что по историческим меркам беспрецедентный экономический рост в XX веке и повышение уровня жизни и ее качества в немалой степени связаны с вкладом женщин в общественное производство.

В новых условиях женщина будет более свободна от необходимости трудиться для заработка, так что создаются условия для возврата женщины в семью и созданию условий для рождения и воспитания детей. Если распространение получит система выплат всем членам общества фиксированного дохода, то рождение детей и получение выплат на них может стать доходным делом для семей. При сложившимся типе воспроизводства населения это приведет к росту численности населения, но такой рост не будет вызван ни биологической (выживание популяции), ни экономической (рост рабочей силы) необходимостью. Таким образом, рост населения за счет повышения рождаемости будет нерационален для общества. Вместе с тем подобного рода модель достаточно долго существует в капиталоизбыточных арабских странах-нефтеэкспортерах. В Саудовской Аравии при высоких доходах, урбанизации и модернизации система социальной поддержки местного населения консервирует высокую рождаемость. Однако в последние годы она стала падать, поскольку продолжительное время такое состояние общество сохранять не может.

Определенным аналогом ситуации в Саудовской Аравии в развитых странах может стать выплата фиксированного дохода всем гражданам страны.

Базовый доход (basic income) представляет собой периодические выплаты без какихлибо условий каждому гражданину страны вне зависимости от того, работает он или нет. Этот доход имеет следующие характеристики.

Периодичность: он выплачивается на регулярной основе (например, раз в месяц), а не как разовая выплата.

Денежная форма: выплата происходит в денежной форме, что позволяет получателю решать, как использовать полученные денежные средства. Это не пособие в натуральной форме, как, например, продовольственные талоны или бесплатные медицинские услуги, и не ваучер на специфические цели.

Индивидуальная форма: платят каждому человеку, а не, например, домохозяйству.

Универсальность: выплата идет всем без прохождения проверки на обеспеченность средствами существования. 
Безусловность: платят всем вне зависимости от того, работает человек или нет, демонстрирует он желание работать или нет.

Как подчеркивает Basic Income European Network 6 , в настоящее время обсуждается много вариантов выплаты базового дохода. Они различаются по величине выплат, их источнику, основаниям для сокращения выплат и величине подобных сокращений, а также другим параметрам.

Эксперимент по выплате базового дохода с 2017 г. начала проводить Финляндия. В течение двух лет 2 тыс. финских безработных в возрасте от 25 до 58 лет будут получать базовый доход в 560 евро вместо всех остальных социальных выплат. Эта сумма будет выплачиваться, даже если получатели найдут работу. Социальные службы Финляндии пошли на такой эксперимент, чтобы повысить мотивацию безработных к поиску занятости, поскольку сейчас, получив работу, человек может потерять часть дохода, так как зарплата может быть меньше пособия по безработице ${ }^{7}$.

При любом результате эксперимента будет получен интересный опыт применения базового дохода на практике.

Если базовый доход становится основным источником дохода и при рождении каждого ребенка выплаты увеличиваются, становится рациональным иметь детей и их воспитывать. Женщина может уйти из работы по найму, а семейное воспитание детей станет доходным занятием.

Противоположной тенденцией может стать отказ от деторождения и даже вступления в брак при сокращении рынка труда, низких и нестабильных доходах и отсутствии гарантий получения стабильного дохода в будущем. Такая ситуация складывается в Японии и Южной Корее, где трудосберегающие технологии наиболее развиты. В Южной Корее была создана эффективная система образования с развитым высшим техническим образованием. Еще недавно диплом университета обеспечивал карьеру и высокий и стабильный доход, но в последние годы ситуация изменилась. Сложилось поколение, которое вынуждено отказываться от того, что раньше было естественной частью жизни. В корейском языке появились термины для обозначения степени отказа от социальных связей и борьбы за благосостояние. Наиболее известный термин - Sampo generation. Это люди, которые отказываются от брака и рождения детей 8 .

Описанные выше ситуации значимы для развитых стран, завершивших демографический переход. Для развивающихся стран и ряда переходных экономик большую актуальность имеет продолжающийся рост численности населения, который в Африке к югу от Сахары все еще очень значителен.

Демографический прогноз ООН в редакции 2015 г. по среднему сценарию предусматривает существенный рост мирового населения, хотя темпы роста замедлятся.

\footnotetext{
${ }^{6} \mathrm{http}: / /$ basicincome.org/about-bien/ (дата обращения: 15.02.2017).

${ }^{7}$ http://www.cnbc.com/2017/01/03/finland-experiments-universal-basic-income.html (дата обращения: 23.03.2017).

${ }^{8}$ https://www.koreabang.com/2015/stories/koreas-gives-up-generation.html (дата обращения: 20.02.2017).
} 
Если в качестве оценки численности рабочей силы признать возрастную группу 15-59 лет, то ее численность будет расти на протяжении всего XXI века. Глобализация экономических процессов, наряду с выросшей миграционной подвижностью населения, делает рынок труда также глобальным. Роботизация и другие трудосберегающие технологи даже при том, что они значительно развиты и распространены в ограниченном числе стран, будут влиять на все страны и мировой рынок труда.

Таблица 2. Демографический прогноз, мир в целом

\begin{tabular}{|c|c|c|c|}
\hline & 2015 г. & 2050 г. & 2100 г. \\
\hline Численность населения мира в целом, млн чел. & 7349,5 & 9725,1 & 11213,3 \\
\hline Доля людей в возрасте 15-59 лет, \% & 61,7 & 57,2 & 54,0 \\
\hline Число людей в возрасте 15-59 лет, млн чел. & 4534,6 & 5562,8 & 6055,2 \\
\hline
\end{tabular}

Источник: [WPP 2015].

Возникает вопрос, как будет функционировать экономика развивающихся стран, когда прогресс роботизации сделает ненужным импорт продукции обрабатывающей промышленности развитыми странами. Возможно, развивающимся странам придется разрабатывать новую модель экономического развития без ориентации экспорта в развитые страны с опорой на внутренний спрос. Этот спрос в условиях, когда подавляющая часть населения бедна, может быть обеспечен только за счет повышения роли государства в экономических процессах, кейнсианской модели регулирования экономики и значительной внешней помощи. Повысится роль перераспределительных процессов в ущерб рыночным механизмам.

Повышается вероятность формирования очагов нестабильности и несостоявшихся государств, в которых многочисленные когорты молодого безработного населения будут источником пополнения как террористических организаций с идеологической базой, так и криминальных банд.

Для развивающихся стран с избыточной рабочей силой и сегодняшним уровнем технологий новая система производительных сил может оказаться опасной тенденцией. Перед большинством развивающихся стран будет стоять необходимость сочетать опору на внутренние ресурсы с получением помощи со стороны развитых. Такой вариант развития, как экспортоориентированная обрабатывающая промышленность, успешно работавший на протяжении примерно полстолетия, уходит в прошлое с развитием робототехники.

\section{Становление новой возрастной структуры населения}

Старение населения в развитых странах теперь не означает, что экономический рост там остановится из-за сокращения численности рабочей силы. Роботы в промышленности и услугах могут заменить рабочую силу. Сильной стороной развитых стран является высокий уровень развития человеческого потенциала. Он может стать основой для роста и развития экономики при сокращающейся численности населения. Разработка и производство робототехники, а также ее эффективное применение требуют комплекса научных знаний и трудовых навыков, высокой дисциплины труда и развитой инфраструктуры для ведения бизнеса. Все это обеспечивается только рабочей силой высокого качества, а это качество тесно связано с уровнем развития человеческого потенциала. 
Проблемы старения населения, которые нарастают в КНР, самой крупной стране по численности населения, наиболее успешном государстве в группе переходных экономик и потенциальном лидере мировой экономики по объему ВВП в ближайшие десятилетия, могут быть успешно решены. Это снимает опасения, что старение населения вызовет экономический спад в КНР и отбросит эту страну назад в социально-экономическом развитии. Такого рода кризис имел бы существенные отрицательные глобальные последствия.

\section{Поворот международных миграций}

Как следствие указанного выше трудовая иммиграция в развитые страны из развивающихся перестает быть необходимым условием экономического роста в первых. Наиболее интересен опыт Японии. Эта страна имеет очень высокую долю старших возрастных групп в населении, рабочая сила сокращается, но трудовая иммиграция практически отсутствует. Промышленность продолжает развиваться в значительной степени за счет роботизации.

В развивающихся странах рост населения в трудоспособном возрасте все еще значителен (таблица 2), а местный рынок труда не способен поглотить всех ищущих работу. Закрытие рынка рабочей силы развитых стран станет большой проблемой для стран развивающихся.

Современная глобализация усиливает такую опасность, поскольку международные миграции населения при росте связности всех составляющих современного глобального общества, включая информационные каналы и транспортные пути, становятся естественной частью глобализационных процессов. Отгородиться от иммиграции странам Запада не удается уже сейчас, как это показывает иммиграционный кризис в ЕС в 2015-2016 гг., а потенциальные потоки иммигрантов будут только нарастать [Щербакова 2016].

Производительное оборудование, основанное на применении робототехники, будет подталкивать фирмы развитых стран экспортировать продукцию на рынки развивающихся стран, что создаст дополнительные проблемы для экономического роста и решения социальных проблем в тех развивающихся странах Азии, Африки и Латинской Америки, которые не сумеют включиться в новую систему производительных сил.

Переселиться в развитые страны даже при самой либеральной иммиграционной политике стран Запада сможет лишь небольшая часть населения развивающихся стран, так что необходимо будет формировать новые стратегии догоняющего развития. Необходимо рассмотреть возможность свертывания глобализации в ряде аспектов. Раз промышленный экспорт не способен выполнять прежнюю функцию локомотива экономического развития для развивающихся стран, индустриализация может носить импортозамещающий характер. В то же время даже Индия (классический образец развития в рамках этой стратегии) отказалась от импортозамещения как основы развития в 1990-е годы и в ходе экономических реформ значительно повысила темпы экономического роста. Таким образом, импортозамещение как основа развития для развивающихся стран имеет определенные ограничения и риски. Оно может отрицательно влиять на экономическую эффективность, если не основано на притоке капиталов и технологий из развитых стран. 
Запад может отгородиться от развивающихся стран в ходе роботизации экономики, но это не означает уход с мировых рынков капитала и промышленной продукции, так что конкуренция с импортными товарами на рынках развивающихся стран сохранится. Помимо западных конкурентов, производители из самих развивающихся стран будут формировать конкурентную среду в странах Азии, Африки и Латинской Америки. Роль international governance, международных институтов регулирования развития будет сильно возрастать.

\section{Урбанизация и внутренние миграции}

В области внутреннего развития может поменяться отношение к такой составляющей модернизации, как урбанизация. Она была неотьемлемой частью развития в эпоху, когда основой развития была размещавшаяся в городах обрабатывающая промышленность. Если обрабатывающая промышленность перестанет быть драйвером экономического развития, то для развивающихся стран более важным механизмом социально-экономического развития может стать сельская модернизация. В этих странах не решена продовольственная проблема. Многие виды сельского хозяйства могут быть вполне эффективны при землесберегающей системе производства, когда наличие труда не лимитировано, а земли мало.

Концепция двух технологических способов производства в сельском хозяйстве выделяет трудосберегающий технологический способ, когда нововведения в сельском хозяйстве были направлены на экономию труда (страны Северной Америки, Европы, Австралия, Аргентина, Россия, Казахстан), а сельское население переходило в город в несельскохозяйственные отрасли. Землесберегающий технологический способ развивался в странах Востока, где мало земли, а трудовые ресурсы имеются в изобилии. Прогресс сельского хозяйства при этой модели развития состоит в увеличении производительности земли через ирригацию, удобрения и т.д. Производительность труда здесь повышается мало [Дерюгина 2015: 11-12].

В новых условиях сохранение населения в сельской местности может оказаться более экономически выгодным, поскольку будет решаться продовольственная проблема и не будет множиться городская безработица. Вместе с тем развитие современной инфраструктуры в сельской местности будет более дорогостоящим проектом, чем урбанизация.

Для развивающихся стран с быстро растущим населением выявлена тенденция политической нестабильности при быстром росте городского населения. При росте городской молодежи темпом более $30 \%$ за пятилетие риск кровопролитных политических потрясений вырастает до $50 \%$, т.е. половина стран при таком темпе роста городского населения рискует попасть в ситуацию острого политического конфликта с кровопролитными столкновениями. Эти выводы сделаны на основе изучения истории 29 стран Азии, Африки и Латинской Америки в 1960-2005 гг. [Коротаев и др. 2011: глава 18].

Таким образом, урбанизация, которая была неотъемлемой частью модернизации и социально-экономического развития, в сочетании с индустриализацией грозит стать опасным явлением, если промышленность, создающая многочисленные рабочие места в городе, не будет развиваться. 


\section{СЦЕНАРИИ}

Bсе описанные выше процессы будут развиваться достаточно интенсивно. Основные промышленные центры мира: США, ЕС, Япония и КНР, - разработали и реализуют программы развития робототехники [Акимов 2016а: 114-125]. Конечно, есть сферы труда, где применение упомянутых трудосберегающих технологий будет ограничено. Это услуги физическим лицам, например медицина, в частности хирургия и другие медицинские манипуляции с больными, уход за больными и престарелыми, образование; такие отрасли, связанные с промышленным производством и услугами в этой сфере, как создание техники и ее обслуживание, компьютерное программирование в производственной сфере и в создании компьютерных игр и других продуктов для досуга. Будет давать новые рабочие места государственная служба в разных ее проявлениях, поскольку государство больше заинтересовано в создании рабочих мест, чем в рационализации. Тем не менее структура занятости претерпит существенные изменения, которые повлияют на самые разные аспекты жизни общества.

Таким образом, страны мира в результате демографического роста будут сталкиваться с проблемами, отличающимися от тех, что преобладали в последние десятилетия. Развитые страны вышли на такой уровень развития технологий и экономики, что и проблемы, связанные с нехваткой природных ресурсов, которые волновали политиков, бизнес и общественность этих стран ранее, и проблемы старения населения вполне решаемы при том технологическом и экономической потенциале, которым эти страны обладают. Развивающиеся страны в то же самое время сталкиваются как с проблемами жизнеобеспечения, так и со старением населения. Кардинально меняется роль труда в экономике. Такого сочетания ранее не было, и развитие этой ситуации ставит целый ряд практических вопросов, выходящих далеко за пределы науки и имеющих важное значение для перспектив социально-экономического развития.

В целом можно определить две группы сценариев развития демографических процессов в условиях качественно нового уровня развития трудосберегающих технологий. Первый - благоприятный для демографических и социально-экономических процессов вариант. Это некоторое повышение рождаемости в развитых странах и ее понижение в развивающихся, продолжение сокращения смертности и повышение продолжительности жизни, становление новой географической структуры международных миграций с сокращением потока трудовой миграции в развитые страны, регулирование внутренних миграций и урбанизации в развивающихся странах.

Второй - неблагоприятный. Это еще большее сокращение рождаемости в развитых странах, но медленное еe сокращение в развивающихся, прекращение роста продолжительности жизни из-за проблем с финансированием здравоохранения, сохранение значительных миграций из развивающихся стран в развитые и рост городов в развивающихся странах без роста промышленности и современного сектора услуг.

В реальных условиях отдельные элементы сценариев будут сочетаться по-разному в разных странах, создавая большое многообразие вариантов, но в условиях глобализации ситуация в отдельных странах или группах стран может оказывать значительное влияние на многие другие государства. 
В этих условиях резко вырастает значимость всех аспектов социальной и демографической политики во всех группах стран. Новые технологии кардинально поменяют рынок труда и социальные условия и механизмы, которые были созданы или стихийно сформировались в прежних условиях. Потребуется создание новых механизмов и структур и перестройка имеющихся для устойчивого социально-экономического развития в новых условиях.

Примерами актуальности проблем разработки будущих моделей развития являются перспективы освоение заполярных районов Сибири и подготовка рабочих в обрабатывающей промышленности России. Приведенный в этой статье пример про экономическое освоение пустынных районов Австралии показывает, что освоение возможно без заселения. Распространение станков с ЧПУ и роботов в обрабатывающей промышленности во всех развитых странах мира показывает, что готовить нужно не станочников, а специалистов по обслуживанию нового поколения техники. Как показывают примеры успешного прогноза, приведенные в этой статье, экономисты и демографы имеют профессиональный потенциал для предвидения и анализа воздействия технологий на социально-экономические процессы.

\section{ЛИТЕРАТУРА}

Акимов А.В. (2016а). Робототехника: состояние и перспективы развития в мире и России // Поиск, альтернативы, выбор. 2: 114-125.

Акимов А.В. (2016b). Демографический взрыв, старение населения и трудосберегающие технологии: взаимодействие в XXI в. // Мировая экономика и международные отношения. 4. 60: 50-60.

Араб-Оглы Э.А. (1986). Обозримое будущее. Социальные последствия НТР: год 2000. М.: Мысль. $141 \mathrm{c.}$

Вишневский А.Г., Р.В. Дмитриев (2016). Глобальные демографические процессы в XX начале XXI веков // География мирового развития. Вып. 3. Сб. научных трудов / Под ред. Л.М. Синцерова. М.: Товарищество научных изданий КМК: 197-229.

Дерюгина И.В. (2015). Сельское хозяйство мира: прошлое и будущее 1980-2010-2050. М.: Изд-во «Перо». $128 \mathrm{c.}$

Коротаев А.В., Ю.В. Божевольнов, Л.Е. Гринин, Ю.В. Зинькина, С.В. Кобзева (2011). К прогнозированию политической нестабильности в странах Африки на период до 2050 г. // Проекты и риски будущего. Концепции, модели, инструменты, прогнозы. М.: КРАСАНД: 357-379.

Леонтьев В. (1990). Экономические эссе. Теории, исследования, факты и политика. М.: Изд-во политической литературы. 415 с.

Спенс М. (2013). Следующая конвергенция: будущее экономического роста в мире, живущем на разных скоростях. М.: Изд-во института Гайдара. 336 с.

Форд М. (2016). Роботы наступают. Развитие технологий и будущее без работы. М.: Альпина нон-фикшн. 430 с.

Шваб К. (2017). Четвертая промышленная революция. М.: Издательство «Э». 208 с. 
Щербакова Е. (2016). По оценке ООН, в 2015 году насчитывалось 244 миллиона международных мигрантов // Демоскоп Weekly. 703 - 704. URL: http://demoscope.ru/weekly/2016/0703/barom01.php (дата обращения: 12.02.2017).

Friedrichs G., A. Schaff, eds. (1982). Microelectronics and society. For better or for worse. Oxford: Pergamon Press. 353 p.

OICA (2015). Production statistics 2015. URL: http://www.oica.net/category/productionstatistics/2015-statistics/ (дата обращения 15.02.2017).

WHO (2017). Health expenditure ratios, by country, 1995-2014. New York: United Nations. URL: http://apps.who.int/gho/data/view.main.HEALTHEXPRATIONOR?lang=en (дата обращения: 23.02.2017).

WPP (2015) World population prospects. The 2015 revision. Key findings \& advance tables. New York: UN. 66 p. 


\title{
HOW ROBOTICS AND LABOR-SAVING TECHNOLOGIES IMPACT POPULATION CHANGE: TRENDS AND SCENARIOS
}

\section{ALEXANDER AKIMOV}

\begin{abstract}
Robots and other labor-saving technologies such as numerical control machine tools, additive technologies, artificial intelligence and large production complexes in mining are replacing human beings in manufacturing. The shrinking labor market will influence fertility, health care financing (and thus mortality), as well as both internal and international migration, especially in developing countries.
\end{abstract}

The departure of women from the labor market may lead to an increase in fertility, especially if the state introduces a guaranteed income for each of its members. At the same time, unemployment may lead to a significant decrease in fertility and in the desire to have children.

Artificial intelligence in medicine may improve the quality of diagnostics and reduce the costs of medical services, thus leading to lower mortality, but decreasing tax revenue and personal income may slow down rising life expectancy or even bring it to a halt.

At the same time, labor-saving technologies will solve the problem of labor shortages resulting from an aging population.

Today's international migration patterns may change dramatically, since labor immigrants will no longer be needed in developed economies. The modernization model for developing countries which took shape in the 20th century, consisting of industrialization and urbanization, may disappear as a result of a shrinking labor market in modern industry and services. Urbanization alone, with no industrialization, results in political disturbance and even bloodshed, as shown by the experience of developing states in the years 1960 2005.

Both positive and negative scenarios of population change may result from the development of labor-saving technologies. The result will mainly depend on the management of social and demographic processes.

Keywords: robotics, labor-saving technologies, fertility, healthcare, mortality, migration, urbanization, trends, scenarios.

AleXander V. Akimov (akimovivran@mail.ru), Institute of Oriental Studies, Russian ACAdemy of SCIENCES, RUSSIA.

DATE RECEIVED: FEBRUARY 2017.

\section{REFERENCES}

Akimov A.V. (2016a). Robototekhnika: sostoyanie i perspektivy razvitiya v mire i Rossii [Robotics: the present state and perspectives in the world and in Russia] // Poisk, al'ternativy, vybor [Search, alternatives, choice]. 2: 114-125.

Akimov A.V. (2016b). Demograficheskiy vzryv, starenie naseleniya i trudosberegayushchie tekhnologii: vzaimodeystvie v XXI v. [Demographic explosion, population aging and laborsaving technologies: interaction in the XXI century] Mirovaya ekonomika i mezhdunarodnye otnosheniya [World economy and international relations]. 4. 60: 50-60.

Arab-Ogly E.A. (1986). Obozrimoe budushchee. Sotsial'nye posledstviya NTR: god 2000 [Observable future. Social aftermath of scientific and technological revolution]. Moscow: Mysl'. 141 p. 
Derjugina I.V. (2015). Sel'skoe khozyaystvo mira: proshloe i budushchee 1980-2010-2050 [Agriculture of the world: the past and future 1980-2010-2050]. Moscow: Izdatel'stvo "Pero". 128 p.

Ford M. (2016). Roboty nastupayut. Razvitie tekhnologiy i budushchee bez raboty [Robots are coming. Technological development and a future without jobs]. Moscow: Al'pina non-fikshn. $430 \mathrm{p}$.

Friedrichs G., A. Schaff, eds. (1982). Microelectronics and society. For better or for worse. Oxford: Pergamon Press. 353 p.

Korotayev A.V., YU.V. Bozhevolnov, L.Ye. Grinin, YU.V. Zinkina, S.V. Kobzeva (2011). K prognozirovaniyu politicheskoy nestabil'nosti v stranakh Afriki na period do $2050 \mathrm{~g}$. [Towards the prediction of political instability in African countries for the period to 2050] // Proekty i riski budushchego. Kontseptsii, modeli, instrumenty, prognozy [Projects and risks of the future. Concepts, models, tools, forecasts]. Moscow: KRASAND: 357-379.

Leont'ev V. (1990). Ekonomicheskie esse. Teorii, issledovaniya, fakty i politika [Economic essays. theories, studies, facts, and politics]. Moscow: Izdatel'stvo politicheskoy literatury. $415 \mathrm{p}$.

OICA (2015). Production statistics 2015. URL: http://www.oica.net/category/productionstatistics/2015-statistics/ (accessed 15.02.2017).

Scherbakova E. (2016). Po otsenke OON, v 2015 godu naschityvalos' 244 milliona mezhdunarodnykh migrantov [According the UN, there were 244 million international migrants in the world in 2015] // Demoscope Weekly. 703 - 704. URL: http://demoscope.ru/weekly/2016/0703/barom01.php (accessed: 12.02.2017).

Shvab K. (2017). Chetvertaya promyshlennaya revolyutsiya [The fourth industrial revolution]. Moscow: Izdatel'stvo «E». 208 p.

Spens M. (2013). Sleduyushchaya konvergentsiya: budushchee ekonomicheskogo rosta v mire, zhivushchem na raznykh skorostyakh [The next convergence: the future of economic growth in the different speed world]. Moscow: Izdatel'stvo instituta Gaydara. 336 p.

Vishnevsky A.G., R.V. Dmitriev (2016). Global'nye demograficheskie protsessy v XX - nachale XXI vekov [Global Demographic Processes in the XX and in the Beginning of the XXI Century] // Geografija mirovogo razvitija. Vyp. 3. Sb. nauchnyh trudov [Geography of world development . Is. 3. Research papers] / L.M. Sincerov, ed. Moscow: Tovarishchestvo nauchnykh izdaniy KMK: 197-229.

WHO (2017). Health expenditure ratios, by country, 1995-2014. New York: United Nations. URL: http://apps.who.int/gho/data/view.main.HEALTHEXPRATIONOR?lang=en (accessed: 23.02.2017).

WPP (2015) World population prospects. The 2015 revision. Key findings \& advance tables. New York: UN. 66 p. 